\title{
Analysis of Cystic Fibrosis in Federation of Bosnia and Herzegovina
}

\author{
Amina Selimovic ${ }^{1}$, Ermina Mujicic ${ }^{2}$, Selma Milisic ${ }^{3}$, Senka Mesihovic-Dinarevic ${ }^{1}$, Amra Dzinovic ${ }^{1}$, \\ Selma Cengic ${ }^{1}$, Ganimeta Bakalovic ${ }^{1}$, Mahir Moro ${ }^{4}$, Meliha Djozic ${ }^{5}$, Lada Lukic-Bilela ${ }^{6}$
}

\author{
${ }^{1}$ Pediatric Clinic of the University Clinical Centre of Sarajevo, Sarajevo, Bosnia and Herzegovina \\ ${ }^{2}$ Department for Cardioanesthesiology, Clinic for anesthesiology, reanimation and intensive care of the University Clinical Center \\ of Sarajevo, Sarajevo, Bosnia and Herzegovina \\ ${ }^{3}$ Sarajevo Medical School, Sarajevo School of Science and Technology, Sarajevo, Bosnia and Herzegovina \\ ${ }^{4}$ Department of Orthopedic Surgery, General Hospital “Prim.dr.Abdulah Nakaš”, Sarajevo, Bosnia and Herzegovina \\ ${ }^{5}$ Department of Ophthalmology, General Hospital“Prim.dr.Abdulah Nakaš”, Sarajevo, Bosnia and Herzegovina \\ ${ }^{6}$ Department of Biology, Faculty of Science, University of Sarajevo, Sarajevo, Bosnia and Hezegovina
}

Corresponding author: Amina Selimović, MD, PhD. Pediatric Clinic of the University Clinical Centre of Sarajevo, Bolnička 25, Sarajevo, Bosnia and Herzegovina. Phone:+38761 564 894; E-mail: amina.selimovic@hotmail.com

\begin{abstract}
Aim: The aim of this study is to present the first total number of tested children in the Federation of Bosnia and Herzegovina and the number of children with positive sweat test. During the study we determined the number of ill children, the median age of children with cystic fibrosis, date of initial diagnosis, an average amount of chloride in the sweat. Material and methods: The study was a retrospective, conducted at the Department of Pulmonology Pediatric Clinic of University Clinical Center of Sarajevo. Results: In the period from March 2003 to December 2014, we have tested 625 children. 351 child were from Sarajevo Canton and 272 children from other cantons. Female children were more affected then male children, in the ratio of 1: 1,105. An average age of female children was $4.19 \pm 4.26$ years, and the male $2.15 \pm 3.11$ years. The median concentration of chloride in the sweat measured by sweat test was for male children $103.05 \pm 21.29$ $\mathrm{mmol} / \mathrm{L}$, and for the female children $96.05 \pm 28.85 \mathrm{mmol} / \mathrm{L}$. Conclusion: Most of children in Federation of Bosnia and Herzegovina have $\triangle \mathrm{F} 508$ gene mutation. In the post-war period we started to use a sweat test. Male children tend to live longer than female children with CF. Key words: cystic fibrosis, sweat test, pilocarpine iontophoresis, chloride, sodium.
\end{abstract}

\section{INTRODUCTION}

Cystic fibrosis (CF) or mucoviscidosis is a multisystem inflammatory disorder where the primary cause of morbidity and mortality is pulmonary destruction, characterized by chronic inflammation, bacterial colonization and frequent exacerbations $(1,2)$.

CF is an autosomal-recesive disease caused by mutations in the CF transmembrane conductance regulator (CFTR) protein at the chromosome 7q31.2 (CFTR $\Delta$ F508). The mutation is a deletion of the three nucleotides that comprise the codon for phenylalanine at position 508. Mutations of the CFTR gene affecting chloride ion channel function lead to dysregulation of epithelial fluid transport in the lung resulting in cystic fibrosis (3 -7). In the United States approximately 30, 000 individuals have CF, and in Canada 4,000 (8). In the European Union, 1 in 2000-3000 newborns is found to be affected by $\mathrm{CF}(5,6,7)$. CF occurs in one of every 3,200 live white births, and in 1 of every
15,000 live African American births, 1 of every 31,000 live Asian Americans births (2, 8).

In normal conditions, CFTR regulates the normal absorption of sodium ions $\left(\mathrm{Na}^{+}\right)$from the lumen of the channel gland, by controlling the function of neighboring epithelial sodium channel $(\mathrm{ENaC})$. In $\mathrm{CF}$ this control is missing, which leads to excessive absorption of $\mathrm{Na}^{+}$in the epithelial cells. Inhibit secretion of $\mathrm{Cl}^{-}$and $\mathrm{Na}^{+}$hyperabsorption lead to the withdrawal of water from the lumen of the secretory canals of glands and secretion in them remains dehydrated and viscous and difficult to be removed by normal mucociliary mechanisms. This leads to obstruction of the airway lumen and a suitable basis for the development of pathogenic microorganisms $(1,2,9)$.

In the thick layer of dense and tenacious secretions airway gradually create anaerobic conditions, which encourages bacteria to adjustment, especially pseudomonas, with the formation of alginate and mucous form of growth (10). 
Cystic fibrosis is a chronic progressive disease that affects multiple organ systems and whose manifestations related primarily to the development of chronic lung disease and malnutrition. Common CF symptoms are: salty-testing skin, slow weight gain, abnormal bowel movements, wheezing, cough and increased lung mucus, pneumonia, nasal polyps, clubbing, severe constipation, meconium ileus, rectal prolapse, pancreatic insufficiency, multifocal biliary cirrhosis, male infertility,etc $(1,2,9)$.

Diagnosis is made by finding elevated levels of chloride in the sweat test. Sweat test is used to measure chloride and sodium levels in sweat. They can be performed at any time from 1 week of age, but adequate sweat volumes may not be obtained before 6 weeks of age. If there is any clinical suspicious of CF, a sweat test should be arranged, even if the patient has had newborn screening, since approximately $5 \%$ of CF cases are not detected by newborn screening. Sweat electrolyte values in adults are often higher than children and need to be interpreted by an expert. The sweat glands are made to produce sweat with a mild chemical called pilocarpine and a little electricity (pilocarpine iontophoresis) $(11,12)$.

Sweat-testing involves application of a medication that stimulates sweating (pilocarpine). To deliver the medication through the skin, iontophoresis is used to, whereby one electrode is placed onto the applied medication and an electric current is passed to a separate electrode on the skin. The resultant sweat is then collected on filter paper or in a capillary tube and analyzed for abnormal amounts of sodium and chloride. People with CF have increased amounts of sodium and chloride in their sweat (11).

The reference ranges of sweat chloride that are currently accepted for the diagnosis of CF in infants up to and including 6 months of age are: equal to or less then 29 $\mathrm{mmol} / \mathrm{L}$ means CF is very unlikely, $30-59 \mathrm{mmol} / \mathrm{L}$ means that CF is possible, greater than or equal to $60 \mathrm{mmol} / \mathrm{L}$ means CF is likely to be diagnosed. The reference ranges of sweat chloride that are currently accepted for the diagnosis of CF in people older than 6 months of age are: equal to or less then $39 \mathrm{mmol} / \mathrm{L}$ means CF is very unlikely, $40-59 \mathrm{mmol} / \mathrm{L}$ means that CF is possible, greater than or equal to $60 \mathrm{mmol} / \mathrm{L}$ means $\mathrm{CF}$ is likely to be diagnosed $(1,11)$.

The test is carried out by collecting sweat from pilocarpine iontophoresis in two or more occasions and chemical determination of the concentration of chloride. The conditions other than cystic fibrosis, which are associated with elevated concentrations of sweat electrolytes include malnutrition, adrenal insufficiency, glycogen storage diseases, anorexia, celiac disease, hypothyroidism, hypoparathyroidism, nephrogenic diabetes inspidus, ectodermal dysplasia, atopic eczema, and congenital metabolic disease. Most of errors are caused by using unreliable methodology, irregular way of collecting sweat, technical errors and misinterpretation of results $(1,2,11)$.

\section{PATIENTS AND METHODS}

We retrospectively analyzed all hospital records at the Pediatric Clinic of University Clinical Center of Sarajevo between March 2003 and December 2014. We included all resident patients of the Federation of Bosnia and
Herzegovina, consisting of Canton Sarajevo and 9 other cantons. We selected all patients with positive sweat test, and also recorded age, gender, date of initial diagnosis, amount of chloride in the sweat test, the number of patients in Federation of Bosnia and Herzegovina.

\section{Statistical analysis}

Statistical analysis was performed using SPSS 20.0 (SPSS, Chicago, IL, USA). In the analysis of the difference between the observed group was used Pearson's test, chi-square test, Ficher exact test, Yates' chi-square test with correction for small samples (with tables in which the number of cells in less than 5), and Student's t-test and One-way analysis of variance (ANOVA), depending on the type of data. The results of these statistical tests were considered statistical significance at $\mathrm{p}<0.05$ or at the level of $95 \%$. The analysis was performed using the statistical package SPSS Statistics IBM v21.0 (Chicago, Illinois, USA).

\section{RESULTS}

During the 11-year period we registered 40 cases of cystic fibrosis. Nineteen were male children and twenty-one female children. The median age in all patients $(n=40)$ with cystic fibrosis was 3,22 $\pm 3,85$ years (interquartile range 0 to 15 years). The median age for male children $(19 / 40)$ was $2.15 \pm 3.11$ years, and for female children $(21 / 40) 4.19 \pm 4.26$ years. There was no significant age dif-

\begin{tabular}{|c|c|c|c|c|c|}
\hline \multicolumn{6}{|c|}{ Year of discover of CF*Gender } \\
\hline & & & \multicolumn{2}{|c|}{ Gender } & \multirow{2}{*}{ Total } \\
\hline & & & Male & Female & \\
\hline \multirow{22}{*}{ 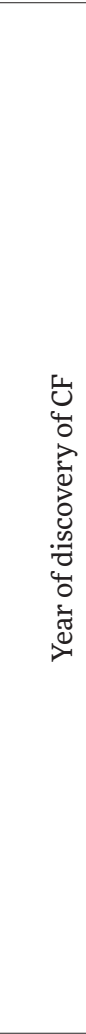 } & \multirow{2}{*}{2003} & $\mathrm{~N}$ & 0 & 3 & 3 \\
\hline & & $\%$ & 0,0 & 14,3 & 7,5 \\
\hline & \multirow{2}{*}{2004} & $\mathrm{~N}$ & 2 & 1 & 3 \\
\hline & & $\%$ & 10,5 & 4,8 & 7,5 \\
\hline & \multirow{2}{*}{2005} & $\mathrm{~N}$ & 2 & 1 & 3 \\
\hline & & $\%$ & 10,5 & 4,8 & 7,5 \\
\hline & \multirow{2}{*}{2006} & $\mathrm{~N}$ & 3 & 2 & 5 \\
\hline & & $\%$ & 15,8 & 9,5 & 12,5 \\
\hline & \multirow{2}{*}{2007} & $\mathrm{~N}$ & 1 & 2 & 3 \\
\hline & & $\%$ & 5,3 & 9,5 & 7,5 \\
\hline & \multirow{2}{*}{2008} & $\mathrm{~N}$ & 2 & 1 & 3 \\
\hline & & $\%$ & 10,5 & 4,8 & 7,5 \\
\hline & \multirow{2}{*}{2009} & $\mathrm{~N}$ & 3 & 1 & 4 \\
\hline & & $\%$ & 15,8 & 4,8 & 10,0 \\
\hline & \multirow{2}{*}{2010} & $\mathrm{~N}$ & 0 & 2 & 2 \\
\hline & & $\%$ & 0,0 & 9,5 & 5,0 \\
\hline & \multirow{2}{*}{2011} & $\mathrm{~N}$ & 3 & 4 & 7 \\
\hline & & $\%$ & 15,8 & 19,0 & 17,5 \\
\hline & \multirow{2}{*}{2012} & $\mathrm{~N}$ & 3 & 2 & 5 \\
\hline & & $\%$ & 15,8 & 9,5 & 12,5 \\
\hline & \multirow{2}{*}{2014} & $\mathrm{~N}$ & 0 & 2 & 2 \\
\hline & & $\%$ & 0,0 & 9,5 & 5,0 \\
\hline \multirow{2}{*}{ Total } & & $\mathrm{N}$ & 19 & 21 & 40 \\
\hline & & $\%$ & 47,5 & 52,5 & 100,0 \\
\hline
\end{tabular}

Table 1. The gender distribution of patients by the year of discovery 
ference $(t=2.912 ; d f=39 ; p=0.096)$ between male and female children.

The total number of sick children (male and female) from March 2003 to December 2014 was 40, 19 male children and 21 female children. Analysis of the frequency of gender according to the year of diagnosis of cystic fibrosis showed that the largest number of children fell ill in 2011, seven. The minimum number of detected children was in 2010, two children (Table 1). There was no statistically significant differences in male compared to female children by the year of discovery $C F,\left(X^{2}=9.801 ; \mathrm{df}=22\right.$; $\mathrm{p}=0.458)$.

Pilocarpine iontophoresis or "sweat test" is a method used to measure an average amount of chloride in the sweat of children. An average amount of chloride in the sweat in male children (19/40) was $103.05 \pm 21.26 \mathrm{mg} / \mathrm{L}$, (interquartile range 60 to $131 \mathrm{mmol} / \mathrm{L}$ chloride); and in the female children $89.71 \pm 22.95 \mathrm{mmol} / \mathrm{L}$ (interquartile range 60 to $128 \mathrm{mmol} / \mathrm{L}$ chloride).. The total average amount of chloride in sweat at all affected children was $96.05 \pm 28.89 \mathrm{mmol} / \mathrm{L}$ (interquartile range 60 to 131 $\mathrm{mmol} / \mathrm{L}$ chloride). The lowest measured amount of chloride, which was enough to confirm the diagnosis of cystic fibrosis in male and female children was $60 \mathrm{mmol} / \mathrm{L}$ in sweat, while the maximum amount of chloride in male children in sweat was $131 \mathrm{mmol} / \mathrm{L}$, in the female children $128 \mathrm{mmol} / \mathrm{L}$. According to the analysis there was no statistically significant difference $(t=3.612 ; d f=39 ; p=0.046)$ between the average amount of chloride by gender (Figure 1).

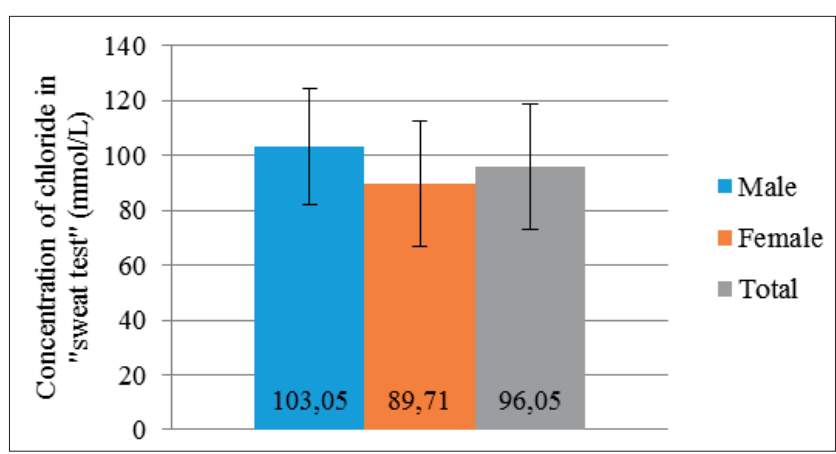

Figure 1. An average amount of chloride in sweat by gender

Children from the Federation of Bosnia and Herzegovina consisting of Canton Sarajevo and other cantons, are tested at the Pulmonary Department of the Pediatric Clinic at the University Clinical Center Sarajevo. The total number of tested children in the Federation was 625 for

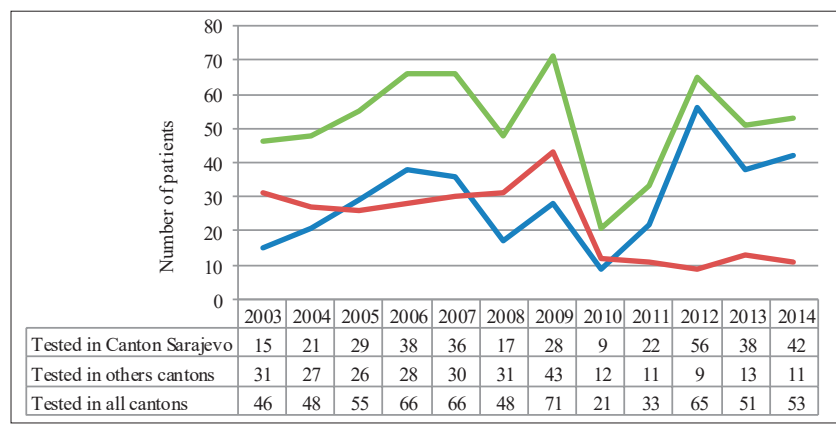

Figure 2. The demographic distribution of patients with CF in the Federation of Bosnia and Herzegovina the period 2003-2014 years, while the number of children tested just in the Sarajevo Canton was 351, and from others cantons 272 children (Figure 2).

Pseudomonas aeruginosa is a common cause of respiratory infections in chronically sick children with $\mathrm{CF}$, and there is a colonization with Pseudomonas aeruginosa. The data are from 2008 to 2014, and pseudomonas was isolated in 13 children 36 times, mostly two and more time per each child (Table 2).

\begin{tabular}{lccc}
\hline & Year & $\begin{array}{c}\text { Number of } \\
\text { children }\end{array}$ & Times \\
\hline \multirow{3}{*}{ Canton Sarajevo } & 2012 & 3 & 6 \\
\cline { 2 - 4 } & 2013 & 1 & 2 \\
\cline { 2 - 4 } & 2014 & 3 & 7 \\
\hline \multirow{3}{*}{ Other cantons } & 2008 & 1 & 4 \\
\cline { 2 - 4 } & 2009 & 1 & 4 \\
\cline { 2 - 4 } & 2010 & 1 & 5 \\
\hline Total & 2012 & 1 & 4 \\
\hline
\end{tabular}

Table 2. The evidence of infected children with P.aeruginosa (2008-2014)

\section{DISCUSSION}

This study shows for the first time the number of children suffering from CF in the Federation of Bosnia and Herzegovina from March 2003 to December 2014.

Advanced diagnostics led to the diagnosis in the early stages of the disease which greatly facilitates the further treatment of patients and thus prolongs the life span.

Seventy years ago patients died in the first year of life most of malabsorption and diarrhea. Today, patients experience the second and third decade, and life expectancy is determined by duration of pulmonary disease. Survival of patients with CF has dramatically improved since the disease was discovered, 70 years ago. Progressive pulmonary disease is leading to morbidity and pulmonary arrest, and the average life expectancy of people with 37.4 years, 37 years for women and 40 years for men $(13,14)$. Progress in the length of life of patients is the result of many new improvement in treating disease. Progress has been made in the diagnosis of CF and the introduction of neonatal screening. It is possible to act on intracellular events and encourage, correct or potentiate the synthesis of mutated CFTR-a (Ivacafor, Lumocaftor, Ataluran), (15, $16,17)$. In the final stage lung disease is available and lung transplantation, individuals with CF must have both lungs replaced because the remaining lung might contain bacteria that could infect the transplanted lung (18). Although the lifespan moved from childhood to adult age, patients are still faced with an abundance of therapeutic needs, and their doctors with a new pathology. The challenge is identifying new manifestations and complications of the disease as well as the actual carrying out of treatment. A special, more a problem in the treatment of patients with CF becomes a problem of economic sustainability of therapy.

Respiratory tract infections and prevent colonization of $\mathrm{P}$. aeruginosa is one of the fundamental problems in the 
treatment of CF. In this sense, nowadays there are many therapeutic strategies that must be counted and the possibility of active immunization against bacterial and viral infections (19). By 18 years of age, $80 \%$ of patients with classic CF harbor P. aeruginosa, and 3.5\% harbor B. cepacia (20).

In cystic fibrosis (CF) lung occupy a special place, because it in most patients with CF are determined by the quality and length of life. The lung is an organ that before birth is not affected by the changes, but soon after birth becomes a place of chronic infection and inflammation. The main goal of therapy in CF is focused primarily on the lungs, and that means delay and reduce the damage and thereby contribute to the quality and duration of life expectancy of CF patients. Therapy of CF today are not causal, or untreated primary disorder, but is based on the treatment of a number of consequences that illness affects many organ systems.

\section{CONCLUSION}

Children born with CF today have a greater chance of living longer, thanks to early diagnosis and multidisciplinary approach to treatment, where children may benefit from treatment with mitigation damaged ionic transport with medications such as inhalers, mucolytics, antibiotics, anti-inflammatory drugs, and methods of cleaning the airways.

Male children with CF tend to live longer than female children with CF, and there is no gender ("sex gap"). Socioeconomic status may affect the length of life of the sick and environmental factors, exposure to cigarette smoke, air pollutants.

Children with CF have a majority of $\Delta \mathrm{F} 508$ genetic mutation. The most difficult patients in the post-war period were from the Central Bosnia Canton, while lately the number of children from Canton Sarajevo with manifestations of harder lung obstruction has risen but without growth deformation and changes in radiogram like in post-war children. Whether this can be explained by new mutations of children with CF or not, time will tell.

Due to the progression, cystic fibrosis is inseparably associated with infection of lungs. P.aeruginosa is the most common bacterial species involved in respiratory tract infection in CF, while Burkholderia have also been identified as causing infection of CF patients.

\section{CONFLICT OF INTEREST: NONE DECLARED.}

\section{REFERENCES}

1. Mishra A, Greaves R, Massie J. The Relevance of Sweat Testing for the Diagnosis of Cystic Fibrosis in the Genomic Era. Clin Biochem Rev. 2005; 26(4): 135-153.

2. O'Sullivan BP, Freedman SD. Cystic fibrosis. Lancet. 2009: 373(9678): 1891-904.

3. Rowe SM, Miller S, Sorscher EJ. Cystic fibrosis. N Engl J Med. 2005; 352(19): 1992-2001.

4. Bobadilla JL, Macek Jr M, Fine JP, Farrell PM. Cystic fibrosis: a worldwide analysis of CFTR mutations-correlation with in- cidence data and application to screening. Human Mutation. 2002; 19(6): 575-606.

5. Dodge JA, Lewis PA, Stanton M, Wilsher J. Cystic fibrosis mortality and survival in the UK: 1947-2003. Eur Respir J. 2007; 29: 522-526.

6. Farell PM. The prevalence of cystic fibrosis in the European Union. J Cyst Fibros. 2008; 7(5): 450-453.

7. Southern KW, Munck A, Pollitt R, Travert G, Zanolla L, Dankert-Roelse J et al. A survey of newborn screening for cystic fibrosis in Europe. J Cyst Fibros. 2007; 6(1): 57-65.

8. Marshal CB. Cystic Fibrosis Foundation Patient Registry: Annual Data Report to the Center Directors. Maryland:Cystic Fibrosis Foundation;2014 [citated 2014 May 15]. Available from: http://www.cff.org/UploadedFiles/aboutCFFoundation/AnnualReport/2013-nnual-Report.pdf

9. Ratjen FA. Cystic fibrosis: Pathogenesis and Future Treatment Strategies. Repir Care. 2009; 54(5): 595-605.

10. Starner TD, McCray PB. Pathogenesis of Early Lung Disease in Cystic Fibrosis: A Window of Opportunity To Eradicate Bacteria. Ann Intern Med. 2005; 143(11): 816-822.

11. Voter KZ, Ren CL. Diagnosis of Cystic fibrosis. Clinic Rev Allerg Immunol. 2008; 35(3): 100-106.

12. Chernick V. Test for the Concentration of Electrolytes in Cystic Fibrosis of the Pancreas Utilizing Pilocarpine by Iontophoresis, by Lewis E. Gibson and Robert E. Cooke.Pediatrics. 1998; 102(1 Pt 2): 230-231.

13. Verma N, Bush A, Buchdahl R. Is there still a gender gap in cystic fibrosis? Chest. 2005; 128(4): 2824-2834.

14. MacKenzie T, Gifford AH, Sabadosa KA, Quinton HB, Knapp EA, Goss CH, Marshall BC. Longevity of patients with cystic fibrosis in 2000 to 2010 and beyond: survival analysis of the cystic fibrosis foundation patient registry. Ann Intern Med. 2014; 161(4): 233-241.

15. Ren, HY, Grove DE, De La Rosa O, Houck SA, Sopha P, van Goor F, Hoffman BJ, Cyr DM. VX-809 corrects folding defects in cystic fibrosis transmembrane conductance regulator protein through action on membrane-spanning domain 1. Mol Biol Cell. 2013; 24(19): 3016-3024.

16. Wilschanski M, Miller LL, Shoseyov D, Blau H, Rivlin J, Aviram M, Cohen M, Armoni S, Yaakov Y, Pugatsch T, Cohen-Cymberknoh M, Miller NL, Reha A, Northcutt VJ, Hirawat S, Donnelly K, Elfring GL, Ajayi T, Kerem E. Chronic ataluren (PTC124) treatment of nonsense mutation cystic fibrosis. Eur Respir J. 2011; 38(1): 59-69.

17. McPhail GL, Clancy JP. Ivacaftor: the first therapy acting on the primary cause of cystic fibrosis. Drugs Today. 2013; 49(4): 253-260.

18. Belkin RA, Henig NR, Singer LG, Chaparro C, Rubenstein RC, Xie SX, Yee JY, Kotloff RM, Lipson DA, Bunin GR. Risk factors for death of patients with cystic fibrosis awaiting lung transplantation. Am J Respir Crit Care Med. 2006; 173(6): 659-666.

19. Henry RL, Mellis CM, Petrovic L. Mucoid Pseudomonas aeruginosa is a marker of poor survival in cystic fibrosis. Pediatr Pulmonol. 1992; 12(3): 158-161.

20. Kumar V, Stanley RL, Aster J. Robbins basic pathology. 5th ed.Philadelphia, Saunders, Philadelphia, 2007. 